Department of Environmental and Occupational Health, Box 13, Hunter Building. University of Newcastle, Newcastle, New South Wales 2308, Australia

David Christie professor of environmental and occupational health

Correspondence to: Harry Hemingway, International Centre for Health and Society, Department of Epidemiology and Public Health, University College London Medical School, London WC1E 6BT h.hemingway@ public-health.ucl.ac.uk margins of the ribs at the level of the right hemidiaphragm. In all, $1191(99 \%)$ of the subjects were flagged at the NHS Central Registry and there were 534 deaths over 25 years, 196 of which were due to coronary heart disease (ICD-8 codes 410-414). Adjusted mortality hazard ratios and their confidence intervals were estimated by Cox's proportional hazards regression models.

The table shows the extent to which cardiothoracic ratio affects the risk of death from all and coronary causes independently of potential confounders. After age, blood pressure, heart rate, total cholesterol concentration, smoking, prevalent symptoms of coronary heart disease, and electrocardiographic evidence of ischaemia were adjusted for, men with a cardiothoracic ratio in the highest fifth of the distribution had a hazard ratio of $1.65(95 \%$ confidence interval 1.01 to 2.70 ) for coronary heart disease mortality compared with men with a cardiothoracic ratio in the lowest fifth. When men with a ratio $\geqslant 0.5$ were excluded, the top fifth $(\geqslant 0.47$ and $<0.5)$ was associated with an increased risk of coronary death of $1.67(0.99$ to 2.82) after age and blood pressure were adjusted for.

\section{Comment}

The cardiothoracic ratio in a healthy middle aged population predicted coronary mortality over 25 years independent of blood pressure and other risk factors. A ratio of $\geqslant 0.5$ has by convention been defined as a threshold of pathological enlargement. In our healthy population of civil servants a ratio of 0.47 to $<0.5$ was associated with increased risk of death from coronary heart disease, questioning this convention. The results of recently established population based echocardiographic studies are therefore awaited to establish the relative contribution of left ventricular mass and left ventricular systolic dysfunction in predicting coronary heart disease among healthy middle aged subjects. Until then the Whitehall study offers the advantage of a prolonged follow up.

Does lowering cardiothoracic ratio reduce the risk of coronary heart disease? Among hypertensive patients, drug treatment and exercise may reduce cardiothoracic ratio. However, further studies are required to investigate whether such effects lead to a reduction in subsequent coronary heart disease events and therefore constitute a worthwhile therapeutic goal. In the meantime the prognostic information provided by the cardiothoracic ratio should be considered in risk stratification of healthy middle aged men.

Contributors: $\mathrm{HH}$ posed the research question and wrot the first draft of the paper. All the authors commented on drafts of the paper which were incorporated by HH. MS carried out all the statistical analyses. DC collected the radiographic data and his doctoral thesis formed the basis of this paper. MM is codirector of the original Whitehall study. $\mathrm{HH}$ is the guarantor.

Funding: MM is supported by an Medical Research Council research professorship. MS is supported by the British Heart Foundation.

Conflict of interest: None.

1 Chambers J. Left ventricular hypertrophy: an underappreciated coronary risk factor. BMJ 1995;311:273-4.

2 Davis JL, Murphy ML, Blue LR, Ferris EJ. A comparison of objective measurements on the chest roentgenogram as screening tests for right or left ventricular hypertrophy. Am J Cardiol 1986;58:658-60.

3 Rautaharju PM, Lacroix AZ, Savage DD, Haynes SG, Madans JH, Wolf $\mathrm{HK}$, et al. Electrocardiographic estimate of left ventricular mass versus radiographic cardiac size and the risk of cardiovascular disease mortality in the epidemiologic follow-up study of the first national health and nutrition examination survey. Am J Cardiol 1988;62:59-66.

4 Reid DD, Brett GZ, Hamilton PJS, Jarrett RJ, Keen H, Rose G. Cardiorespiratory disease and diabetes among middle aged male civil servants. Lancet 1974;i:469-73.

5 Christie D. Physical correlates of radiologic heart volume. Acta Radiol Diag 1978;19:732-6.

(Accepted 24 June 1997)

\title{
Adherence to cardiac rehabilitation guidelines: a survey of rehabilitation programmes in the United Kingdom
}

\author{
Robert J P Lewin, Rosie Ingleton, Andrew J Newens, David R Thompson
}

Editorial by deBono

Institute of

Rehabilitation,

Faculty of Health,

University of Hull,

Hull HU3 2PG

Robert J P Lewin,

professor of

rehabilitation

Rosie Ingleton,

research assistant

Andrew J Newens,

senior lecturer in

nursing

David R Thompson, professor of nursing

continued over

BMJ 1998;316:1354-5
Two key recommendations of recent guidelines are that cardiac rehabilitation requires the skills of a range of professionals and that the patient should receive a menu based programme after an individual assessment of needs. ${ }^{1}$ A previous survey of 25 cardiac rehabilitation programmes found little congruence with these guidelines and noted that physicians were particularly unlikely to be involved. ${ }^{2}$ We extended this inquiry to include all of the discoverable rehabilitation programmes in the United Kingdom.

\section{Subjects, methods, and results}

We identified 273 cardiac rehabilitation programmes through registers maintained by professional and charitable bodies and conducted a structured telephone interview with the "main coordinator" of 263 $(96 \%)$ of these programmes between 1 April 1996 and
31 March 1997. If a respondent did not have the competence to answer a particular question the appropriate person was contacted. We asked each participant whether the rehabilitation team included anyone from a list of nine healthcare professions. To examine the use of assessment measures we asked which of a list of 15 health variables were assessed; whether this was with a validated assessment (a published scale or a standardised procedure with known properties) or an informal assessment (any other method); and whether the assessment was repeated either to check the patient's progress or to audit outcome.

Most (184 (70\%)) participants reported that five or more (mean 4.6; SD 1.6) healthcare professions were represented on the rehabilitation team; only $13(5 \%)$ teams comprised members from only one profession. Nurses were represented in 234 (89\%) teams, dieticians in $220(84 \%)$, and physiotherapists in 223 (85\%). Less 
Number (percentage) of programmes $(n=263)$ that conducted validated or informal assessments and which repeated these assessments at any time

\begin{tabular}{lccc} 
Factor assessed & $\begin{array}{c}\text { Validated } \\
\text { assessment }\end{array}$ & $\begin{array}{c}\text { Informal } \\
\text { assessment }\end{array}$ & $\begin{array}{c}\text { Repeat } \\
\text { assessment }\end{array}$ \\
\hline Blood pressure & $204(76)$ & 0 & $156(59)$ \\
\hline Lipids & $196(75)$ & 0 & $56(21)$ \\
\hline Electrocardiographic stress test & $136(52)$ & 0 & $17(6)$ \\
\hline Exercise capacity & $94(36)$ & $73(28)$ & $115(44)$ \\
\hline Weight & $65(25)^{*}$ & $98(37) \dagger$ & $93(35)$ \\
\hline Symptoms of heart disease & $2(1)$ & $101(38)$ & $94(36)$ \\
\hline Diet & 0 & $72(27)$ & $34(13)$ \\
\hline Smoking & $8(3)$ & $252(96)$ & $195(74)$ \\
\hline Knowledge of heart disease & 0 & $31(12)$ & 0 \\
\hline Anxiety & $70(27)$ & $11(4)$ & $77(29)$ \\
\hline Depression & $70(27)$ & $10(4)$ & $71(27)$ \\
\hline Stress & $8(3)$ & $34(13)$ & $26(10)$ \\
\hline Sleep & $3(1)$ & $18(7)$ & \\
\hline $\begin{array}{l}\text { Sexual and personal } \\
\text { relationships }\end{array}$ & 0 & $18(7)$ & $7(3)$ \\
\hline Suitability for work & 0 & $44(17)$ & $18(7)$ \\
\hline
\end{tabular}

${ }^{*}$ Body mass index was calculated.

tOnly weight was measured.

than half of the participants reported that their team included an occupational therapist (106 (40\%)), a physician (103 (39\%)), a psychologist (55 (21\%)), a health promotion officer $(43(20 \%))$, or a social worker or vocational counsellor $(37(14 \%))$.

In a random sample of 120 programmes, further questions were asked about the degree to which each profession took part in the programme. For each profession previously mentioned the participant was asked whether that professional (a) gave talks to patients, or otherwise took part in the programme and (b) saw each patient individually. In only a small proportion of teams did a physician (19 teams (16\%)), a psychologist $(11(9 \%))$, a health promotion officer (7 $(6 \%))$, or a social worker or vocational counsellor (1 (1\%)) give talks to patients or otherwise take part in the programme. It was rare for professions other than nurses (83 teams (69\%)) and physiotherapists (79 $(66 \%))$ to see patients individually-occupational therapists $(18(15 \%))$, dietician $(7(6 \%))$, physician $(8(7 \%))$, health promotion officer $(1(1 \%))$, social worker $(1(1 \%))$.

The number and percentage of programmes that conducted validated or informal assessments and which repeated these assessments at any time is shown in the table. Blood pressure (204 programmes (78\%)) and measurement of lipid concentration (195 (74\%)) were most commonly available; however, the values for these were often taken from medical records during acute admission and were therefore of limited value to rehabilitation. The assessment of blood pressure was repeated in 59\% of programmes and smoking in 74\% (albeit with a validated measure in only $8(3 \%)$ centres); none of the other measures were repeated in more than half of the programmes.

\section{Comment}

The findings confirm that adherence to the national guidelines $^{1}$ is poor and that few physicians play an active part in rehabilitation programmes. There is little in the way of assessment (a prerequisite for a "menu driven" service) or audit; this is especially worrying as secondary prevention is an important goal of rehabilitation. ${ }^{3}$ Psychosocial factors were particularly poorly assessed despite the fact that it is well established that attention to these is one of the major goals of cardiac rehabilitation. ${ }^{4}$ Those responsible for commissioning a cardiac rehabilitation service should ensure that it is adequately resourced $^{5}$ to allow programmes to be evidence based, menu driven, and properly audited.

Contributors: RJPL had the original idea for the study and coordinated the research. DRT, AJN, and RI contributed to the design of the study and to developing the telephone interview. All interviews were conducted by RI. The paper was written jointly by RJPL and DRT.

Conflict of interest: None.

Funding: No specific funding.

1 Thompson DR, Bowman GS, Kitson AL, de Bono DP, Hopkins A Cardiac rehabilitation in the United Kingdom: guidelines and audit standards. Heart 1996;75:89-93.

2 Thompson DR, Bowman GS, Kitson AL, de Bono DP, Hopkins A. Cardiac rehabilitation services in England and Wales: a national survey. Int J Cardiol 1997;59:299-304.

3 World Health Organisation. Needs and action priorities in cardiac rehabilita tion and secondary prevention in patients with CHD. Copenhagen: WHO Regional Office for Europe, 1993.

4 Lewin R. The psychological component. In: Thompson DR, Bowman GS, de Bono DP, Hopkins A, eds. Cardiac rehabilitation: guidelines and audi standards. London: Royal College of Physicians, 1997:21-45.

5 Audit Commission. Dear to our hearts? Commissioning services for the treat ment and prevention of coronary heart disease. London: HMSO, 1995.

(Accepted 16 December 1997)
Correspondence to: Professor R J P Lewin, British Heart Foundation

Rehabilitation Research Unit, Department of Health Studies, University of York, York YO10 5DQ rjpl1@york.ac.uk

\section{Fifty years ago \\ Why I went to Oxford, not Cambridge}

In December 1947 I went to Cambridge to take an entrance examination. A week later my father-in those days colleges communicated not with the applicant but with the parentreceived a letter from the senior tutor saying that I had done well in my science papers, but in the English paper I had shown no understanding of the poetry in question. I thus could not be accepted, but might resit the following year.

So in March 1948 I spent a week in Oxford taking their exams. Again my science papers, practicals, and vivas went well, and I did not have to attempt any poetry in the general paper, which contained many of the logic problems of Lewis Carroll with which I was already familiar. So I was not only accepted but was also awarded a major scholarship. Are applicants to study medicine in the 1990 s required to be expert in non-scientific topics such as poetry and logic?

Jeremy Hugh Baron, honorary professorial lecturer, New York

We welcome articles up to 600 words on topics such as A memorable patient, A paper that changed my practice, My most unfortunate mistake, or any other piece conveying instruction, pathos, or humour. If possible the article should be supplied on a disk. Permission is needed from the patient or a relative if an identifiable patient is referred to. We also welcome contributions for "Endpieces," consisting of quotations of up to 80 words (but most are considerably shorter) from any source, ancient or modern, which have appealed to the reader. 